\title{
New drug law to speed scientific review
}

By charging drug companies 'user fees' that will be spent hiring new staff, the US Food and Drug Administration will reduce the time it takes to review new pharmaceuticals from an average of two years to one.

FOR years, the US pharmaceutical industry has complained bitterly that the Food and Drug Administration (FDA) is too slow in reviewing and approving new drugs for the medical market. In turn, FDA has said it does not have enough scientific staff to handle more than 100 applications a year any faster than it does. So some valuable medicines have languished in the bureaucracy for years, unavailable to patients who need them.

The urgent need for rapid review has been nowhere more apparent than in the treatment of AIDS, where true medical need, combined with a strong political lobby of so-called AIDS activists, prevailed to convince the FDA to more quickly on the approval of the drugs AZT and DDI, suspending certain requirements of proved efficacy.

A long overdue bill passed last week by the US Congress should go a long way to right that situation (see page 567). But the legislation breaks new ground by subtly changing the relationship between the pharmaceutical industry and FDA by allowing the agency to charge companies substantial 'user fees' to review a drug application. Fees of $\$ 100,000$ per application will apply this year. By 1997 , fees will rise to $\$ 233,000$ per application. It is the first time the FDA has been authorized to charge fees to commercial interests that, by law, must seek its services.

So the threat of the new law had the pharmaceutical companies howling in protest? Surprisingly, not at all. The industry believes that fees of a hundred thousand dollars or more will be well worthwhile if the time from submission to FDA action can be reduced from two years to one for 'ordinary' drugs, and from one year to six months for potentially life-saving drugs for the terminally ill - AIDS and cancer patients, for instance. In the economics of the drug business, companies stand to make millions of dollars for every month cut from the approval process.

This development represents a change of heart. Although the idea of charging fees has been debated for years, the industry has vigorously protested that fees would be grossly unfair unless FDA spent the money solely on speeding the approval process. The fear was that the money would be dispersed throughout the agency or, worse still, would wind up in the US Treasury to be spent on government programmes in general. Only an agreement reached in the past couple of months to limit user fees to the drug review process has broken the deadlock.
With revenues from fees expected to reach $\$ 330$ million within the next five years, FDA Commissioner David Kessler has promised to hire 600 scientists and other professionals to review the safety and efficacy of new drugs. That alone will greatly enhance the overall scientific strength of FDA, which is vital at a time when the number of new drug applications from the biotechnology industry is expected to increase from dozens under review this year to as many as 300 two years from now and, perhaps, as many as 1,200 by the end of the decade.

Two questions remain, of which the more immediate is whether the profits likely to accrue to the pharmaceutical companies will lead to lower drug prices for consumers. Naturally, the companies are promising that faster approval will mean lower prices. They have no choice, having argued in the past that one reason for high prices is that the approval process takes so long. It is tempting, but perhaps naive, to hope that lower prices at the pharmacy counter will derive from this otherwise sound legislation. Perhaps FDA could use some of its new recruits to keep a close eye on drug prices, using what it learns in renewing the Prescription Drug User Fee Act of 1992, which expires in 1997.

The other question is how far the principle of user fees will spread. FDA is not the only regulatory agency whose supplicants complain at the delays in the bureaucracy. People seeking to run television stations or to extract minerals from a mine must also often await permission from the federal government. In its regulatory role, the Environmental Protection Agency is a fruitful source of frustration. It is to be hoped that the new Congress does not take the precedent of the deal with FDA to levy user fees wherever they can be made to stick, which could be unjust.

\section{Biodiversity supported}

Funding for a new programme, with only $\$ \mathbf{1 . 5}$ million for grants, is hardly enough to scratch the surface.

Almost all scientists will agree that it is important to maintain biodiversity on this planet, for the good of the planet and the people who inhabit it. It is also perhaps fair to say that biodiversity does not rank high on the list of concerns facing the average citizens of either developed or 